\title{
Article \\ Cultural Adaptation and Validation of the Quality of Dying in Long-Term Care Scale (QoD-LTC) for Spanish Nursing Homes
}

\author{
Daniel Puente-Fernández ${ }^{1, *(\mathbb{D})}$, Rosel Jimeno-Ucles ${ }^{2}$, Emilio Mota-Romero ${ }^{3}{ }^{\mathbb{D}}$, Concepción Roldán ${ }^{4}$, \\ Katherine Froggatt ${ }^{5}$ and Rafael Montoya-Juárez ${ }^{6}$ (D) \\ 1 Doctoral Program of Clinical Medicine and Public Health, University of Granada, 18012 Granada, Spain \\ 2 Edades Nursing Home, 23160 Jaén, Spain; rju_baeza@hotmail.com \\ 3 Salvador Caballero Primary Care Centre, Andalusian Health Service, 18012 Granada, Spain; \\ emilio.mota.sspa@juntadeandalucia.es \\ 4 Department of Statistics and Operational Research, University of Granada, 18071 Granada, Spain; \\ iroldan@ugr.es \\ 5 Formerly International Observatory on End-of-Life Care, Lancaster University, Lancaster LA1 4YD, UK; \\ kafroggatt@gmail.com \\ 6 Department of Nursing, University of Granada, 18071 Granada, Spain; rmontoya@ugr.es \\ * Correspondence: danielpuentefdz@correo.ugr.es; Tel.: +34-958248751
}

\section{check for} updates

Citation: Puente-Fernández, D.; Jimeno-Ucles, R.; Mota-Romero, E.; Roldán, C.; Froggatt, K.;

Montoya-Juárez, R. Cultural

Adaptation and Validation of the Quality of Dying in Long-Term Care Scale (QoD-LTC) for Spanish Nursing Homes. Int. J. Environ. Res. Public Health 2021, 18, 5287. https:// doi.org/10.3390/ijerph18105287

Academic Editor: Paul B. Tchounwou

Received: 21 April 2021

Accepted: 10 May 2021

Published: 16 May 2021

Publisher's Note: MDPI stays neutral with regard to jurisdictional claims in published maps and institutional affiliations.

Copyright: (c) 2021 by the authors. Licensee MDPI, Basel, Switzerland. This article is an open access article distributed under the terms and conditions of the Creative Commons Attribution (CC BY) license (https:// creativecommons.org/licenses/by/ $4.0 /)$.

\begin{abstract}
Background: There is a need for instruments that can evaluate the psychosocial quality of dying in nursing homes. The aim of this study was to adapt and validate the Quality of Dying in Long-Term Care scale (QoD-LTC) to the Spanish context. Methods: Descriptive cross-sectional study. Fourteen nurses from 7 facilities in southern Spain assessed 153 residents who died in the centers; validity, reliability, and feasibility were evaluated. Results: The Spanish version consists of 11 items with acceptable reliability $(\alpha=0.681)$. Three factors model was validated by principal components analysis. A mean of $180.62(\mathrm{SD}=86.66)$ seconds is needed to fill it in. An inter-observer $0.753(95 \%$ CI: $0.391-0.900, p<0.001$ ) and intra-observer 0.855 (95\% CI: 0.568-0.951 $p=0.001$ ) reliability were observed. Weak correlation was observed; positive with mono-item question (0.322) and negative with Eastern Cooperative Oncology Group (ECOG) with a value of $(-0.321)$ and Integrated Palliative outcome scale (IPOS) with a value of $(-0.252)$. Conclusions: The QoD-LTC scale presents an adequate factorial structure, internal consistency, and feasibility to evaluate psychosocial quality of dying in nursing homes. It can be used as a quality indicator.
\end{abstract}

Keywords: terminal care; nursing homes; long-term care; palliative care; quality of health care; quality indicators

\section{Introduction}

There is an increasing demand for long-term care services such as nursing homes in Western societies [1-3]. This is due to an ageing population and the increasing chronicity and prevalence of multiple diseases [1,2] amongst older people. Nursing homes become the usual place of residence for older people when their care needs become continuous and specialized, beyond the capacity of informal caregivers [2,4]. Therefore, these settings are gaining importance as a place of residence in the last stage of life, given that a significant percentage of older people die in these places [1,5].

Spanish nursing homes offer integral accommodation, either temporary or permanent, to people in a situation of dependence. Their objectives are to achieve a better quality of life and to promote people's personal autonomy, through the provision of intervention programs and activities that respond to the specific needs of its users [6].

The literature shows that residents at the end of life in nursing homes experience symptoms that worsen their quality of life; Smedbäck et al. (2017), in his retrospective study evaluating the last week of life in Swedish nursing homes, showed that the most 
frequent symptoms in the last week of life were pain, anxiety, confusion, shortness of breath and nausea [7]. Similar results have been observed for the Spanish context, where interventions that can be considered futile have also been reported [8].

At the end of life, there are several concepts that need to be identified ("quality of care", "quality of dying" and "quality of death"). Quality of care refers to elements of the environment that occur at death, while quality of dying includes the resident's symptom burden and other experiences that may be influenced by care and various resident-related factors [9]. Quality of dying is considered to be synonymous with quality of life [9]. Quality of death and dying, on the other hand, is defined as "the degree to which a person's preferences for dying and the timing of death are consistent with observations of how the person actually died, as reported by others" [10]. In a recent review, Meier et al. (2016) [10] defined the most representative characteristics of successful dying. Aspects present included "preferences for the dying process" (preparation for death such as advance directives, funeral arrangements), absence of pain, emotional well-being (absence of fear and depression), end of life, treatment preferences, dignity, and family. Since the goals of palliative care include improving the quality of life of patients until death and assisting the family in this process, we can say that palliative care plays a key role in the quality of dying.

Dementia may be another key factor in care provision in these facilities, given that there is a high prevalence in this population $[7,8,11,12]$. Symptoms and treatments at the end of life are different depending on the presence or absence of dementia [11]. Many tools have been developed to assess the quality of dying and deaths $[9,13,14]$, although none of them have been adapted and validated for the Spanish population and for use in nursing homes. One of the most widely used scales to assess the quality of dying in long-term care facilities is the "Quality of dying in Long-Term Care" (QoD-LTC) [15]. This is a scale validated in the United States, which evaluates psychosocial quality of dying at the last month of life of deceased residents and can be used by professionals and family members alike. One of the advantages is that it takes a short amount of time to complete. It can be completed for deceased patients with or without cognitive impairment [16,17]. Due to the retrospective design of this instrument, it can be used as a quality indicator for care provided by nurses at the end of life.

The validation of a scale in one context does not mean that it will automatically be valid at another time, culture, or context [18]. Therefore, when using a tool in a different culture, it is important to go beyond just direct translation to ensure construct validity and reliability and to reduce the risk of introducing bias into the study [19]. This is especially necessary with such individual and dynamic constructs [20]. A number of relationships are involved in this process between the wishes of the dying person, the ability of others to meet their expectations and the degree of social control exercised over this process, all of which are highly dependent on the culture and context [20]. The end-of-life characteristics and significant changes in residents as they are near death [7,8,21-23] make assessment a complex process, with the presence of dementia increasing the difficulties in an assessment $[7,24]$. This is why it is recommended that instead of using Likert-type measures, the items should be evaluated on a continuous basis, with visual analogue scales (VAS). VAS also allow for greater precision in statistical analysis [25-28].

The aim of this study was to adapt the QoD-LTC for Spanish nursing homes and evaluate its psycho-metric properties. It is hypothesized that the Spanish version of the QoD-LTC shows an adequate feasibility, reliability, internal consistency, and satisfactory criterion validity. Also, it is hypothesized that QoD-LTC shows a good convergent validity with different scales that assess the quality of palliative care such as the Integrated Palliative Care Outcome Scale (IPOS), Edmonton Symptom Assessment Scale (ESAS) and nurses' perception of quality of the patient's death process. 


\section{Materials and Methods}

2.1. Design

A two-part study was carried out: (1) cultural adaptation using a Delphi method; (2) validation was carried out by conducting a descriptive cross-sectional study in seven nursing homes in the provinces of Granada and Jaén (Spain) following the procedure proposed by Ramada, Serra and Delclós [29]. A cultural adaptation and validation of the QoD-LTC scale was carried out. Data were collected between May 2018 and February 2019.

\subsection{Sample}

For part one, the cultural adaptation used a Delphi procedure. Thirteen experts in the fields of geriatrics, end-of-life or palliative care were contacted. For this study, an expert is understood as any person with extensive clinical, research and/or teaching experience in one of the fields described above.

For part two, two participating nurses in each nursing home with at least 6 months of experience in the center were recruited. They selected and assessed deceased residents who met the following inclusion criteria: (a) Patients who had died within the last 3 months at the nursing home; (b) Who had spent most of the last month of life (at least three weeks) in the nursing home.

All cases who met the above criteria were consecutively sampled and all the informed consents were obtained. No participant loss was reported by nursing home nurses.

This study was undertaken in accordance with basic ethical principles for the responsible conduct of research involving people. The study received the approval of the Research Ethics Committee (1642-N-17), in compliance with Spanish Law (Law 2/2018). Informed consent was sought from participants. All data were anonymized.

\subsection{Procedure}

\subsubsection{Cultural Adaptation}

For cultural adaptation, the QoD-LTC original scale [15] was translated from English to Spanish and then back to English by two independent bilingual translators. To assess content validity, a synthesis of the translations was evaluated by a committee of experts using the Delphi technique [30]. Experts in geriatrics, end-of-life or palliative care evaluated the relevance, clarity, and levels of meaning and difficulty in response compared to the original language using a Likert-type scale. The agreement was set at $80 \%$.

Once a definitive version was obtained, cognitive interviews were carried out with the first 13 nurses participating in the study. This kind of interview provides information on the way in which individuals process and respond mentally to a questionnaire, to identify factors that may affect the response [31,32]. Cognitive interview records were also used to evaluate feasibility. They were transcribed and read to check that the participants understood the different items.

\subsubsection{Validation}

A form was developed which included the Spanish version of the QoD-LTC scale and sociodemographic and clinical data. Each of the forms was filled in by the nurses for each of the residents. After measurement, the data were entered into a database for further analysis. To assess convergent validity, the Edmonton Symptom Assessment Scale (ESAS) [33], the Integrated Palliative Outcome Scale (IPOS) [34,35], Eastern Cooperative Oncology Group Scale of Performance Status (ECOG) and Quality of dying during the last month (QoD-LM) were included in the form.

To check reliability among observers, $40 \%$ of the cases were randomly selected, and assessments were repeated both by the same nurse (intra-observer reliability) and by another nurse (inter-observer reliability) one week after the first assessment. 


\subsection{Tools}

QoD-LTC [15] is a post-death scale designed to evaluate psychosocial quality of dying at the last month of life of institutionalized residents in nursing homes with 11 items, to which professionals or family members who have cared for the deceased respond to the question "How true is it that ...?". In its original version, it has an internal validity of $\alpha=0.66$ with three subscales (personhood, closure, and preparatory tasks). Higher mean scores reflect a higher quality of end of life in LTC. The original score is proposed in a Likert-type scale from 1 (not true) to 5 (totally), although for our study it was collected using VAS for reasons previously expressed. Once the questionnaires were obtained, they were measured on a millimetric scale [24-27]. For correct use, an explanation of how the scale should be answered was included, with a practical example [27]. Scale.

The following tools were used to assess convergent validity with the QoD-LTC Spanish

- $\quad$ Edmonton Symptom Assessment System (ESAS) [33]. The ESAS scale has been validated to be filled in by professionals, patients, and caregivers with different diseases, being easily completed and interpreted [35]. ESAS was used regularly in all the nursing homes that participated in the study for symptom assessment. Symptoms have been observed on a conceptual level that may interfere with quality of dying [10].

- Integrated Palliative Outcome Scale (IPOS)[34]: IPOS evaluates palliative care needs in the domains of physical and psychosocial functioning. It is a 17-item scale. Symptoms are assessed on a $0-4$ Likert scale. The IPOS was found to be internally consistent, $\alpha$ $=0.77$. Lower scores indicate a better palliative care outcome, the maximum score would be 68. The QoD-LTC scale has been considered to assess the quality of care [9]. In order to assess convergent validity, we have used the IPOS scale.

- $\quad$ Eastern Cooperative Oncology Group Scale of Performance Status (ECOG): it was developed in 1982 and assessing performance status is one such measurement [36]. It describes a patient's level of functioning in terms of their ability to care for him/herself, daily activity, and physical ability (walking, working, etc.). Functional status has been associated with quality of the dying [16].

- Quality of dying during the last month (QoD-LM): How do you consider the quality of the patient's death process to have been during his last month? It was evaluated by means of a Likert scale of 1 Terrible, 2 Bad, 3 Normal, 4 Good, 5 Very Good.

\subsection{Data Analysis}

Descriptive analyses were carried out for sociodemographic and clinical data as well as for feasibility.

The Kaiser-Meyer-Olkin (KMO) test and the Bartlett sphericity test were performed to check whether the scale could be subjected to the factorial analysis of principal components carried out later.

Cronbach's Alpha was calculated for the full scale as well as for each of the subscales. For inter-observer and intra-observer reliability, intra-class correlation coefficient (ICC) was calculated. An ICC of $<0.50$ indicates poor to fair agreement, ICC $=0.5-0.75$ moderate agreement, ICC $=0.75-0.90$ good agreement and ICC $>0.90$ excellent agreement [37]. Kolmogorov-Smirnov normality tests were performed. Due to the non-normal distribution, non-parametric tests were performed for concurrent validity. Spearman's rho correlation coefficients between the QoD-LTC score and the results were obtained for the ECOG, ESAS, IPOS, and QoD-LM.

A Spearman's coefficient of $r<0.39$ indicates weak correlation, $r=0.40-0.69$ indicates moderate correlation, $\mathrm{r}>0.7$ indicates strong correlation [38]. $p<0.05$ was considered significant. IBM SPSS v22.0 [39] was used for data analyses. 


\section{Results}

\subsection{Cultural Adaptation}

The expert committee was composed of 13 experts with an average age of 43.3 (32-58) with an average experience of 13 (6-27) years in geriatric, end-of-life or palliative care. An agreement was arrived at for all the items of the scale and the modification of some items was proposed (Tables A1 and A2). For eight of the items, this consensus was achieved in the second round. For the remaining three items, consensus was achieved in the third round.

A total of 13 cognitive interviews were conducted, in which it was identified that they understood the response mode on the VAS and confirmed the understanding of the modified items. Regarding feasibility, nurses' average response time for the questionnaire was three minutes (180.62 s), with a standard deviation (SD) of $86.66 \mathrm{~s}$.

\subsection{Validation}

\subsubsection{Sample Description}

Fourteen nurses from seven centers participated. The mean age was 32.79 (SD = 7.434) years with a mean nursing home experience of 58.86 months and a standard deviation of 48,648 .

A total of 153 patients were included. The majority of patients who died in nursing homes were women $(56 \%)$; the mean age was $86.12(\mathrm{SD}=11.56)$ years old at the time of death, widows $(60.7 \%)$ and most of them died in the facility $(57.5 \%)$. The most prevalent conditions were dementia (54.9\%) and chronic heart disease (39.9\%) (Table 1).

Table 1. Sociodemographic and clinical characteristics of the residents.

\begin{tabular}{ccc}
\hline Variables & \multicolumn{3}{c}{ Total Sample $\boldsymbol{n}=\mathbf{1 5 3}$} \\
\hline Age, M (SD) & 87.62 & $(11.56)$ \\
Female, $n(\%)$ & 91 & $(59.5)$ \\
Marital status widower, $n(\%)$ & 92 & $(60.7)$ \\
Place of death & 1 & \\
Home, $n(\%)$ & 64 & $(7)$ \\
Hospital, $n(\%)$ & 88 & $(57.5)$ \\
Nursing-Home, $n(\%)$ & 26 & $(17)$ \\
Coexisting conditions & 22 & $(14.4)$ \\
Oncologic disease, $n(\%)$ & 61 & $(39.9)$ \\
Chronic lung disease & 84 & $(54.9)$ \\
Chronic heart disease & 31 & $(20.3)$ \\
Dementia & 21 & $(13.7)$ \\
Vascular neurological disease & 2 & $(1.3)$ \\
Degenerative neurological & 19 & $(12.4)$ \\
disease & & \\
Chronic liver disease & & \\
Chronic kidney failure & & \\
\hline
\end{tabular}

\subsubsection{Factorial Analysis}

The KMO test and Bartlett's test of sphericity were carried out before a factorial analysis $\left(\mathrm{KMO}=0.653 ; \chi^{2}=363.090, p<0.001\right)$. This scale presented three factors (Table 2): Quality of Care, End-of-life communication, and End-of-life appearance. 
Table 2. Factorial load of the QoD-LTC scale adapted to the Spanish context.

\begin{tabular}{|c|c|c|c|}
\hline Items & $\begin{array}{c}\text { Factor 1. Quality } \\
\text { of Care }\end{array}$ & $\begin{array}{l}\text { Factor 2. End-of-Life } \\
\text { Communication by } \\
\text { the Resident }\end{array}$ & $\begin{array}{c}\text { Factor 3. End-of-Life } \\
\text { Appearance }\end{array}$ \\
\hline $\begin{array}{l}\text { [RESIDENT] received } \\
\text { compassionate physical } \\
\text { touch daily. }\end{array}$ & 0.593 & -0.154 & 0.351 \\
\hline $\begin{array}{l}\text { [RESIDENT's] dignity } \\
\text { was maintained. } \\
\text { [RESIDENT's] physician }\end{array}$ & 0.730 & 0.074 & 0.136 \\
\hline $\begin{array}{c}\text { knew }[\mathrm{HIM} / \mathrm{HER}] \text { as a } \\
\text { whole person. }\end{array}$ & 0.848 & -0.177 & 0.096 \\
\hline $\begin{array}{l}\text { There was a nurse or aide } \\
\text { with whom [RESIDENT] } \\
\text { felt comfortable. }\end{array}$ & 0.737 & 0.136 & 0.020 \\
\hline $\begin{array}{l}\text { Someone was designated } \\
\text { to make decisions in their } \\
\text { place [Resident] in the } \\
\text { case that they could no } \\
\text { longer do so. } \\
\text { [RESIDENT] indicated }\end{array}$ & 0.647 & 0.100 & 0.082 \\
\hline $\begin{array}{l}{[\mathrm{HE} / \mathrm{SHE}] \text { was prepared }} \\
\text { to die. }\end{array}$ & -0.182 & 0.728 & 0.178 \\
\hline $\begin{array}{l}\text { [Resident] communicated } \\
\text { their preferences with } \\
\text { respect to treatment. }\end{array}$ & 0.094 & 0.820 & 0.085 \\
\hline $\begin{array}{l}\text { [Resident] expressed how } \\
\text { they wanted their funeral } \\
\text { and/or other matters } \\
\text { concerning their body to } \\
\text { be after their death. }\end{array}$ & 0.258 & 0.638 & -0.419 \\
\hline $\begin{array}{l}\text { [RESIDENT] was kept } \\
\text { clean. }\end{array}$ & 0.362 & -0.094 & 0.410 \\
\hline $\begin{array}{c}\text { [RESIDENT] was able to } \\
\text { retain [HIS/HER] sense } \\
\text { of humor. }\end{array}$ & 0.085 & 0.333 & 0.763 \\
\hline $\begin{array}{c}\text { [HE/SHE] appeared to } \\
\text { be at peace. }\end{array}$ & 0.316 & 0.113 & 0.785 \\
\hline
\end{tabular}

The extraction was based on Principal Component Analysis using the Varimax rotation method with Kaiser normalization. Bold font indicates the factor loading of the item on the factor to which it was assigned.

\subsubsection{Reliability}

The QoD-LTC scale showed an adequate reliability $(\alpha=0.681)$. The $\alpha$ score oscillated among dimensions (Quality of Care $\alpha=0.737$; End-of-life communication $\alpha=0.579$ and End-of-life Appearance $\alpha=0.575$ ). For each item, statistically significant intra- and interclass correlation was obtained. Scores correlation ranged from 0.411 to 0.915 for the intra-observer and from 0.371 to 0.837 for the interobserver (Table 3). An inter-observer ICC $=0.753$ (95\% CI: $0.391-0.900, p<0.001)$ and an intra-observer ICC $=0.855(95 \%$ CI: $0.568-0.951 p=0.001$ ) was observed for total score scale. 
Table 3. Results of intra- and inter-observer variability.

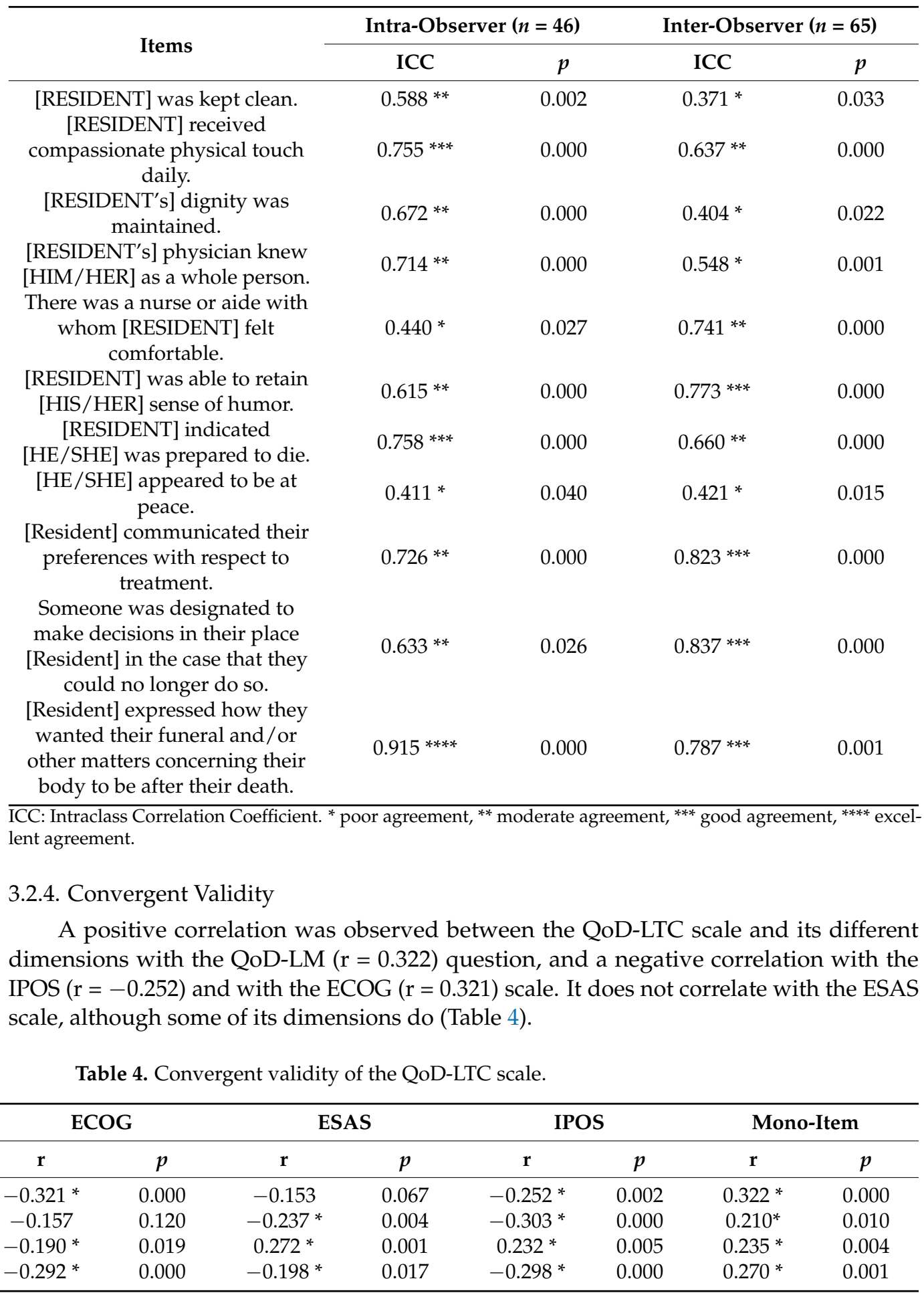

ECOG: Eastern Cooperative Oncology Group Scale of Performance Status; ESAS: Edmonton Symptom Assessment System; IPOS: Integrated Palliative Outcome Scale. Mono-item: Quality of dying during the last month; QoD-LTC: Quality of Dying in Long-Term Care. $\mathrm{r}=$ Spearman's rho; ${ }^{*}=$ weak correlation. $p=p$ value 


\section{Discussion}

In the present study, we carried out the adaptation and validation of the QoD-LTC scale evaluated by nurses in Spanish nursing homes. The culturally adapted version presented an adequate factorial structure and internal consistency. In addition, it showed good internal reliability, as well as inter- and intra-observer reliability. The adapted version of the QoDLTC correlates with the IPOS scale and the single-item question and conversely with the ECOG scale. The modified response method is feasible for use in clinical environments and has not affected the reliability of the scale.

During the cultural adaptation process, the expert group changed items that reflected cultural differences between the Spanish and the American context where the instrument was developed. In a Mediterranean culture, family, community ties and the Catholic religion are seen as important factors that influence experiences toward the end of life [40]. Meñaca et al. [40] identified that the Catholic religion with its associated paternalism shapes how family members participate in the entire process of care. This, combined with a resistance to discuss death with older people, means that in many cases residents delegate end-of-life decisions completely to family members [41].

Regarding the item "[RESIDENT] had treatment preferences in writing", although there is legislation in Spain regulating this practice and advance directives are seen as a positive tool by health professionals, there is evidence that advance directives are not being implemented systematically [42], and a large percentage of the population is unaware of their existence and have never been informed by their doctor about them [43]. The expert group proposed the modification of this item to note the verbal expression of wishes, even if these were not documented, to better reflect cultural practices.

The Spanish version of the QoD-LTC scale showed the same number of factors but a different distribution than the original scale. Our factors are consistent with the qualitative study of the items carried out by Van Soest-Poortvliet et al. (2011) [9], which reported that QoD-LTC primarily assesses the quality of care and the quality of the dying process. Our results coincide with those reported in these studies, where our first factor deals with the quality of care, and the third and fourth items deal with the quality of death.

According to our hypothesis, the adaptation of the QoD-LTC scale presents a similar reliability to the original one ( $\alpha=0.681$ vs. $\alpha=0.66$ ) [15]. This indicates that the adapted scale and the original scale have the same validity. This is also the case for other scales such as the Palliative Outcome Scale (POS) in its original and Spanish version for patients [44,45]. All items showed a statistically significant degree of agreement between different evaluators in assessing the same case with a different grade of agreement. In the same way, the testretest shows a statistically significant result in all evaluated scores.

The negative correlation observed with the IPOS scale reinforces that QoD-LTC evaluates a construct which is similar to the quality of palliative care, having among its components aspects that have been identified as potentially forming part of this construct [9]. Although the weak negative correlation indicates that they are not the same construct. Conversely, the better the scores on the QoD-LTC scale, the better the quality of palliative care.

The non-correlation observed with the ESAS scale shows that psychosocial quality of dying is not related to symptom intensity, as has been observed in other studies [46].

In terms of functionality, it is observed that the worse the functionality, the worse the quality of dying. Low correlation indicates that it is not the same construct. Finally, it has been observed that the general assessment of QoD-LM correlates positively with the results of our scale.

The QoD-LTC scale evaluates psychosocial quality of dying. This construct is different if it is from the perspective of the professional, the family member or the patient [10]. As they are different populations, these changes could affect the psychometric characteristics of the scale, so an individual validation for each population is necessary. Nevertheless, the literature is clear in demonstrating that the QoD-LTC is a useful tool $[9,14,16]$. 
The availability of this revised instrument when adapted will allow researchers in the Spanish context to undertake comparisons with other contexts [16], thus facilitating the extrapolation of data and the development and comparison of intervention programs at the end of life. This approach can be complemented by qualitative analysis and generate mixed-method studies that provide an integrative approach to the clinical reality in this regard, as well as evaluate end-of-life interventions.

It must be pointed out as a limitation that the nursing home facilities are usually private $(71.53 \%)$ [43], so their participation in research studies is voluntary. Similarly, it was not possible to select the original cases randomly, but rather, these were chosen according to whether the patients died within the data collection period (consecutively). Although cases were not randomly selected, the characteristics of the sample coincide with those of other studies in the Spanish population $[8,11,47,48]$. Despite having been evaluated by the expert committee, it would be interesting to test the acceptability and practicability of the scale in nursing homes.

As regards future lines of research, it would be recommended to carry out the adaptation and validation of this instrument into Spanish for its completion by family members, as well as to compare the views of professionals with those of family members, which are different ${ }^{41}$. It would also be interesting to see if this instrument can be filled in by other care home professionals such as physicians, psychologists or social workers. There is further research to be undertaken with specific variables such as underlying health conditions, or the way death occurs, on the QoD-LTC score.

\section{Conclusions}

Validity, reliability, and feasibility of the Spanish version of the QoD-LTC scale have been evaluated, showing psychometric properties comparable to the original version. QoDLTC is a useful scale applicable to the Spanish-speaking context to assess psychosocial quality of dying.

QoD-LTC is an instrument administered and interpreted by nursing professionals that can facilitate resource and care management. It can also guide the evaluation of protocols that aim for a good quality of dying in nursing homes. This instrument can be an indicator of the quality of the end-of-life processes in these centers.

Author Contributions: Conceptualization, D.P.-F., E.M.-R., C.R., K.F., and R.M.-J.; methodology, D.P.-F., E.M.-R., C.R., K.F., and R.M.-J.; validation, D.P.-F., C.R., and R.M.-J.; formal analysis, D.P.-F., R.J.-U., C.R., and R.M.-J.; investigation, D.P.-F., R.J.-U., and R.M.-J.; resources, D.P.-F., R.J.-U., E.M.-R., C.R., and R.M.-J.; writing-original draft preparation, D.P.-F., R.J.-U., E.M.-R., C.R., K.F., and R.M.-J.; writing-review and editing, D.P.-F., R.J.-U., E.M.-R., C.R., K.F., and R.M.-J.; visualization, D.P.-F., R.J.-U., E.M.-R., K.F., and R.M.-J.; supervision, E.M.-R., C.R., K.F., and R.M.-J. funding acquisition, E.M.-R. and R.M.-J. All authors have read and agreed to the published version of the manuscript.

Funding: This research was funded by the Fundación Pública Andaluza Progreso y Salud, grant number (AP-0105-2016).

Institutional Review Board Statement: The study was conducted according to the guidelines of the Declaration of Helsinki, and approved by the Ethics Committee of the Research Ethics Committee of Granada (1642-N-17).

Informed Consent Statement: Informed consent was obtained from all subjects involved in the study.

Data Availability Statement: The data presented in this study are available upon request from the corresponding author. The data are not publicly available due to privacy restrictions

Acknowledgments: We would like to thank all the patients, nursing homes administrators, family members and professionals who have made this study possible. This paper is part of a principal author's PhD Thesis.

Conflicts of Interest: The authors declare no conflict of interest. 


\section{Appendix A}

Table A1. Changes proposed by the experts for the items of the QoD-LTC scale.

\begin{tabular}{cc}
\hline \multicolumn{1}{c}{ Original } & Adaptation. \\
\hline $\begin{array}{c}\text { [RESIDENT] had treatment preferences in } \\
\text { writing. }\end{array}$ & $\begin{array}{c}\text { [Resident] communicated their preferences } \\
\text { with respect to treatment. }\end{array}$ \\
\hline $\begin{array}{c}\text { [RESIDENT] had named a decision-maker in } \\
\text { the event that [HE/SHE] was no longer able to } \\
\text { make decisions. }\end{array}$ & $\begin{array}{c}\text { Someone was designated to make decisions in } \\
\text { their place [Resident] in the case that they } \\
\text { could no longer do so. }\end{array}$ \\
\hline $\begin{array}{c}\text { [RESIDENT] had funeral arrangements } \\
\text { planned. }\end{array}$ & $\begin{array}{c}\text { [Resident] expressed how they wanted their } \\
\text { funeral and /or other matters concerning their } \\
\text { body to be after their death }\end{array}$ \\
\hline
\end{tabular}

\section{Appendix B}

Table A2. ESCALA -QoD-LTC.

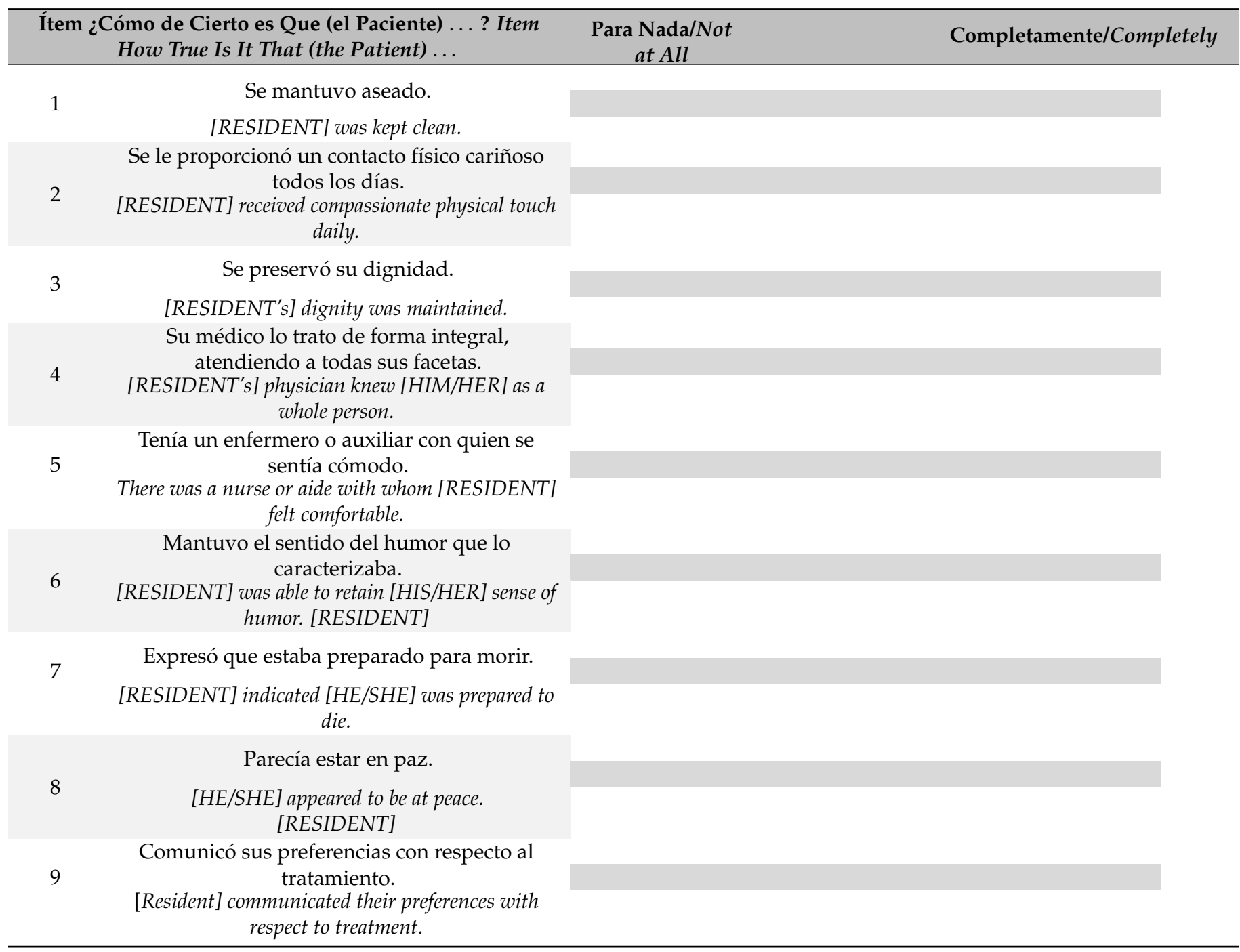


Table A2. Cont.

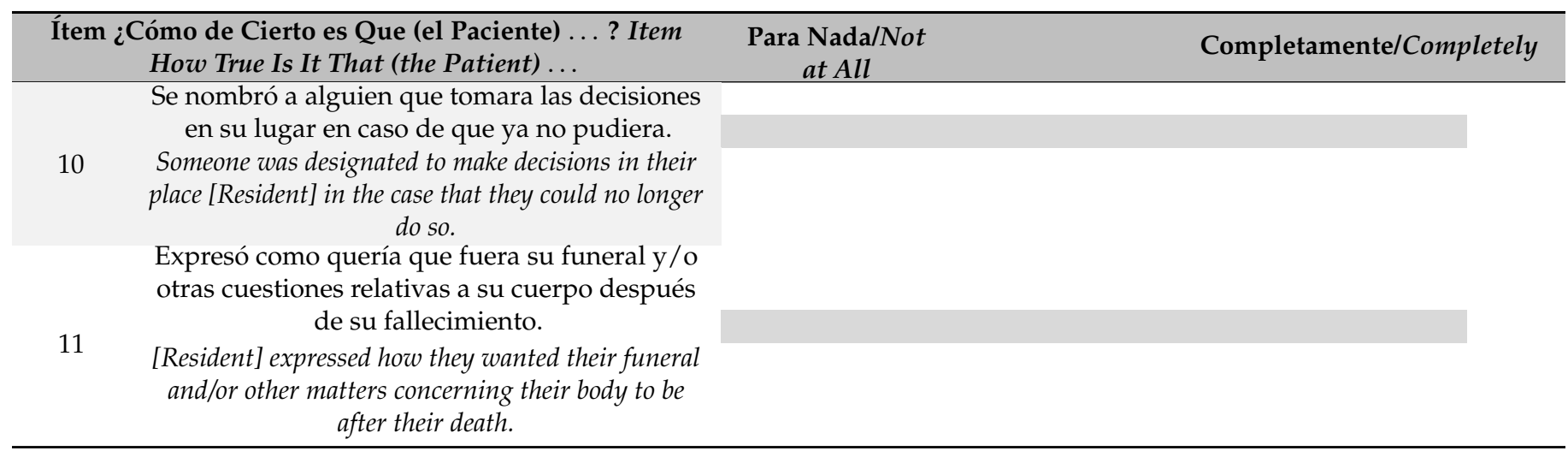

The background colour of the table is where the participants should mark the point where the answer is located.

\section{References}

1. Reitinger, E.; Froggatt, K.; Brazil, K.; Heimerl, K.; Hockley, J.; Kunz, R.; Morbey, H.; Parker, D.; Husebo, B.S. Palliative care in long-term care settings for older people: Findings from an EAPC Taskforce. Eur. J. Palliat. 2013, 20, 251-253.

2. Social Protection Committee. Adequate Social Protection for Long-Term Care Needs in An Ageing Society Report Jointly Prepared by the Social Protection Committee; Publications Office of the EU: Luxembourg, 2014.

3. Spasova, S.; Baeten, R.; Ghailani, D.; Vanhercke, B. Challenges in Long-Term Care in Europe A Study of National Policies. Available online: https: / /ec.europa.eu/social/main.jsp?langId=en\&catId=89\&newsId=9185 (accessed on 7 September 2018).

4. Límón, E.; Blay, C.; Ledesma, A. Population needs, a call for changes in Primary Care. Atención Primaria 2015, 47, 73-74. [CrossRef] [PubMed]

5. Costa, V.; Earle, C.C.; Esplen, M.J.; Fowler, R.; Goldman, R.; Grossman, D.; Levin, L.; Manuel, D.G.; Sharkey, S.; Tanuseputro, P.; et al. The determinants of home and nursing home death: A systematic review and meta-analysis. BMC Palliat. Care 2016, 15, 8. [CrossRef] [PubMed]

6. Ministerio de Sanidad. Servicios Sociales e Igualdad INFORME 2016. Las Personas Mayores en España. Available online: https:/ / www.imserso.es/InterPresent1/groups/imserso/documents/binario/112017001_informe-2016-persona.pdf (accessed on 1 January 2017).

7. Smedbäck, J.; Öhlén, J.; Årestedt, K.; Alvariza, A.; Fürst, C.J.; Håkanson, C. Palliative care during the final week of life of older people in nursing homes: A register-based study. Palliat. Support. Care 2017, 15, 417-424. [CrossRef]

8. Puente-Fernández, D.; Roldán-López, C.B.; Campos-Calderón, C.P.; Hueso-Montoro, C.; García-Caro, M.P.; Montoya-Juarez, R. Prospective Evaluation of Intensity of Symptoms, Therapeutic Procedures and Treatment in Palliative Care Patients in Nursing Homes. J. Clin. Med. 2020, 9, 750. [CrossRef] [PubMed]

9. Van Soest-Poortvliet, M.C.; van Der Steen, J.T.; Zimmerman, S.; Cohen, L.W.; Munn, J.; Achterberg, W.P.; Ribbe, M.W.; De Vet, H.C.W. Measuring the quality of dying and quality of care when dying in long-term care settings: A qualitative content analysis of available instruments. J. Pain Symptom Manag. 2011, 42, 852-863. [CrossRef] [PubMed]

10. Meier, E.A.; Gallegos, J.V.; Montross-Thomas, L.P.; Depp, C.A.; Irwin, S.A.; Jeste, D.V. Defining a Good Death (Successful Dying): Literature Review and a Call for Research and Public Dialogue. Am. J. Geriatr. Psychiatry 2016, 24, 261-271. [CrossRef]

11. Puente-Fernández, D.; Campos-Calderón, C.P.; Esteban-Burgos, A.A.; Hueso-Montoro, C.; Roldán-López, C.B.; Montoya-Juárez, R. Palliative care symptoms, outcomes, and interventions for chronic advanced patients in Spanish nursing homes with and without dementia. Int. J. Environ. Res. Public Health 2020, 17, 1465. [CrossRef] [PubMed]

12. Estabrooks, C.A.; Hoben, M.; Poss, J.W.; Chamberlain, S.A.; Thompson, G.N.; Silvius, J.L.; Norton, P.G. Dying in a Nursing Home: Treatable Symptom Burden and its Link to Modifiable Features of Work Context. J. Am. Med. Dir. Assoc. 2015, 16, 515-520. [CrossRef]

13. Mularski, R.A.; Dy, S.M.; Shugarman, L.R.; Wilkinson, A.M.; Lynn, J.; Shekelle, P.G.; Morton, S.C.; Sun, V.C.; Hughes, R.G.; Hilton, L.K.; et al. A systematic review of measures of end-of-life care and its outcomes. Health Serv. Res. 2007, 42, 1848-1870. [CrossRef] [PubMed]

14. Zimmerman, S.; Cohen, L.; van Der Steen, J.T.; Reed, D.; van Soest-Poortvliet, M.C.; Hanson, L.C.; Sloane, P.D. Measuring end-of-life care and outcomes in residential care/assisted living and nursing homes. J. Pain Symptom Manag. 2015, 49, 666-679. [CrossRef]

15. Munn, J.C.; Zimmerman, S.; Hanson, L.C.; Williams, C.S.; Sloane, P.D.; Clipp, E.C.; Tulsky, J.A.; Steinhauser, K.E. Measuring the quality of dying in long-term care. J. Am. Geriatr. Soc. 2007, 55, 1371-1379. [CrossRef]

16. Pivodic, L.; Smets, T.; van den Noortgate, N.; Onwuteaka-Philipsen, B.D.; Engels, Y.; Szczerbińska, K.; Finne-Soveri, H.; Froggatt, K.; Gambassi, G.; Deliens, L.; et al. Quality of dying and quality of end-of-life care of nursing home residents in six countries: An epidemiological study. Palliat. Med. 2018, 32, 1584-1595. [CrossRef] 
17. Swagerty, D. Integrating Quality Palliative and End-of-Life Care into the Geriatric Assessment: Opportunities and Challenges. Clin. Geriatr. Med. 2017, 33, 415-429. [CrossRef] [PubMed]

18. Abbas, W.A.; Ramadan, M.; Faid, A.Y.; Abdellah, A.M.; Ouf, A.; Moustafa, N.; Allam, N.K. Cross-cultural adaptation of research instruments: Language, setting, time and statistical considerations. BMC Med. Res. Methodol. 2010, 10, 1-10.

19. Sousa, V.D.; Rojjanasrirat, W. Translation, adaptation and validation of instruments or scales for use in cross-cultural health care research: A clear and user-friendly guideline. J. Eval. Clin. Pract. 2011, 17, 268-274. [CrossRef]

20. Krishnan, P. Concept analysis of good death in long term care residents. Int. J. Palliat. Nurs. 2017, 23, 29-34. [CrossRef] [PubMed]

21. Hendriks, S.A.; Smalbrugge, M.; Hertogh, C.M.; van Der Steen, J.T. Dying with dementia: Symptoms, treatment, and quality of life in the last week of life. J. Pain Symptom Manag. 2014, 47, 710-720. [CrossRef] [PubMed]

22. Hoffmann, F.; Kaduszkiewicz, H.; Glaeske, G.; van den Bussche, H.; Koller, D. Prevalence of dementia in nursing home and community-dwelling older adults in Germany. Aging Clin. Exp. Res. 2014, 26, 555-559. [CrossRef]

23. Koppitz, A.; Bosshard, G.; Schuster, D.H.; Hediger, H.; Imhof, L. Type and course of symptoms demonstrated in the terminal and dying phases by people with dementia in nursing homes. Zeitschrift für Gerontol. und Geriatr. 2015, 48, 176-183. [CrossRef]

24. De Witt Jansen, B.; Brazil, K.; Passmore, P.; Buchanan, H.; Maxwell, D.; McIlfatrick, S.; Morgan, S.M.; Watson, M.; Parsons, C. "A tool doesn't add anything". The importance of added value: Use of observational pain tools with patients with advanced dementia approaching the end of life-a qualitative study of physician and nurse experiences and perspectives. Int. J. Geriatr. Psychiatry 2018, 33, 1346-1354. [CrossRef]

25. Kuhlmann, T.; Reips, U.D.; Wienert, J.; Lippke, S. Using visual analogue scales in ehealth: Non-response effects in a lifestyle intervention. J. Med. Internet Res. 2016, 18, 1-9. [CrossRef] [PubMed]

26. Sung, Y.T.; Wu, J.S. The Visual Analogue Scale for Rating, Ranking and Paired-Comparison (VAS-RRP): A new technique for psychological measurement. Behav. Res. Methods 2018, 50, 1694-1715. [CrossRef] [PubMed]

27. Chang, R.; Little, T.D. Innovations for Evaluation Research: Multiform Protocols, Visual Analog Scaling, and the Retrospective Pretest-Posttest Design. Eval. Heal. Prof. 2018, 41, 246-269. [CrossRef] [PubMed]

28. Hjermstad, M.J.; Fayers, P.M.; Haugen, D.F.; Caraceni, A.; Hanks, G.W.; Loge, J.H.; Fainsinger, R.; Aass, N.; Kaasa, S. Studies comparing numerical rating scales, verbal rating scales, and visual analogue scales for assessment of pain intensity in adults: A systematic literature review. J. Pain Symptom Manag. 2011, 41, 1073-1093. [CrossRef]

29. Ramada-Rodilla, J.M.; Serra-Pujadas, C.; Delclós-Clanchet, G.L. Adaptación cultural y validación de cuestionarios de salud: Revisión y recomendaciones metodológicas. Salud Publica Mex. 2013, 55, 57-66. [CrossRef]

30. Margarita, G.; Valdés, I.; Suárez Marín, M. Delphi method for the expert consultation in the scientific research. Rev. Cuba. Salud Pública 2013, 39, 253-267.

31. Muehlhausen, W.; Byrom, B.; Skerritt, B.; McCarthy, M.; McDowell, B.; Sohn, J. Standards for Instrument Migration When Implementing Paper Patient-Reported Outcome Instruments Electronically: Recommendations from a Qualitative Synthesis of Cognitive Interview and Usability Studies. Value Health 2018, 21, 41-48. [CrossRef]

32. Willis, G.B.; Artino, A.R. What Do Our Respondents Think We're Asking? Using Cognitive Interviewing to Improve Medical Education Surveys. J. Grad. Med. Educ. 2013, 5, 353-356. [CrossRef]

33. Carvajal Valcárcel, A.; Martínez García, M.; Centeno Cortés, C. Versión española del Edmonton Symptom Assessment Sytem (ESAS): Un instrumento de referencia para la valoración sintomática del paciente con cáncer avanzado. Med. Paliativa 2013, 20, 143-149. [CrossRef]

34. Murtagh, F.E.M.; Ramsenthaler, C.; Firth, A.; Groeneveld, E.I.; Lovell, N.; Simon, S.T.; Denzel, J.; Guo, P.; Bernhardt, F.; Schildmann, E.; et al. A brief, patient- and proxy-reported outcome measure in advanced illness: Validity, reliability and responsiveness of the Integrated Palliative care Outcome Scale (IPOS). Palliat. Med. 2019, 33, 1045-1057. [CrossRef] [PubMed]

35. Husebo, B.S.; Ballard, C.; Sandvik, R.; Nilsen, O.B.; Aarsland, D. Efficacy of treating pain to reduce behavioural disturbances in residents of nursing homes with dementia: Cluster randomised clinical trial. BMJ 2011, 343, 1-10. [CrossRef]

36. Oken, M.; Creech, R.; Tormey, D.; Horton, J.; Davis, T.; McFadden, E.; Carbone, P. Toxicity And Response Criteria Of The Eastern Cooperative Oncology Group. Am. J. Clin. Oncol. 1982, 5, 649-655. [CrossRef] [PubMed]

37. Koo, T.K.; Li, M.Y. A Guideline of Selecting and Reporting Intraclass Correlation Coefficients for Reliability Research. J. Chiropr. Med. 2016, 15, 155-163. [CrossRef]

38. Schober, P.; Schwarte, L.A. Correlation coefficients: Appropriate use and interpretation. Anesth. Analg. 2018, 126, 1763-1768. [CrossRef] [PubMed]

39. IBM SPSS Statistics 22.0 Available for Download. IBM SPSS Stat. Base 22.0. Available online: https://ibm-spss-statistics-base.en. uptodown.com/windows/download (accessed on 15 April 2019).

40. Meñaca, A.; Evans, N.; Andrew, E.V.W.; Toscani, F.; Finetti, S.; Gómez-Batiste, X.; Higginson, I.J.; Harding, R.; Pool, R.; Gysels, M. End-of-life care across Southern Europe: A critical review of cultural similarities and differences between Italy, Spain and Portugal. Crit. Rev. Oncol. Hematol. 2012, 82, 387-401. [CrossRef] [PubMed]

41. Montoya-Juárez, R. Aquellos que nos verán morir: Significado y respuesta de los profesionales sanitarios deuna residencia de ancianos ante la muerte y los moribundos. Index Enferm. 2006, 15, 791-796. [CrossRef]

42. Sánchez-García, M.R.; Moreno-Rodríguez, M.; Hueso-Montoro, C.; Campos-Calderón, C.; Varella-Safont, A.; Montoya-Juárez, R. Dificultades y factores favorables para la atención al final de la vida en residencias de ancianos: Un estudio con grupos focales. Aten. Primaria 2017, 49, 278-285. [CrossRef] 
43. Centro de Investigaciones sociológicas. Informe Envejecimiento en Red. Available online: http://envejecimientoenred.es/ informes-envejecimiento-en-red/ (accessed on 21 March 2021).

44. Hearn, J.; Higginson, I.J. Development and validation of a core outcome measure for palliative care: The palliative care outcome scale. Palliative Care Core Audit Project Advisory Group. Qual. Health Care 1999, 8, 219-227. [CrossRef]

45. Serra-Prat, M.; Nabal, M.; Santacruz, V.; Picaza, J.M.; Trelis, J.; Barcons, M.; Barnades, S.; Busquet, X.; Carulla, J.; Clols, M.; et al. Traducción, adaptación y validación de la Palliative Care Outcome Scale al Español. Med. Clin. 2004, 123, 406-412. [CrossRef]

46. Caprio, A.J.; Hanson, L.C.; Munn, J.C.; Williams, C.S.; Dobbs, D.; Sloane, P.D.; Zimmerman, S. Pain, dyspnea, and the quality of dying in long-term care. J. Am. Geriatr. Soc. 2008, 56, 683-688. [CrossRef] [PubMed]

47. Blay, C.; Martori, J.C.; Limón, E.; Oller, R.; Vila, L.; Gómez-Batiste, X. Busca tu 1\%: Prevalencia y mortalidad de una cohorte comunitaria de personas con enfermedad crónica avanzada y necesidades paliativas. Aten. Primaria 2019, 51, 71-79. [CrossRef]

48. Puente-Fernández, D.; Palma-Ayllón, E.; Sánchez-García, M.R.; Hueso-Montoro, C.; Esteban-Burgos, A.A.; Montoya-Juárez, R. Development of a Scale Based on Nursing Outcome Classification “Dignified Life Closure" (1307) to Assess End-of-Life Dignity of Patients in Care Homes for the Elderly. Int. J. Nurs. Knowl. 2020, 31, 44-49. [CrossRef] [PubMed] 